\title{
DESIGN, DEVELOPMENT AND FABRICATION OF A MIST SPRAY DIRECT EVAPORATIVE COOLING SYSTEM AND ITS PERFORMANCE EVALUATION
}

\author{
Avinash M. Deshmukh ${ }^{1, *}$, S. N. Sapali ${ }^{1}$
}

\begin{abstract}
In today's essential commodities, air conditioning system is one of the major energy consuming elements. Nowadays evaporative cooling systems are mostly preferred as an alternative to compressor-based air conditioned systems. It is reported that evaporative cooling systems consume 60 - $70 \%$ less energy compared to compressor-based air conditioning systems. In this paper, performance analysis of a mist evaporative cooler is carried out experimentally. The performance parameters such as, drop in temperature, cooling capacity, saturation efficiency, the coefficient of performance are evaluated with respect to various ambient conditions and with a varied mass flow rate of air. Experimental data used to develop an empirical correlation to predict the temperature of cooled air by linear regression analysis. Predicted temperature of cooled air temperature by empirical correlation is validated through experimentation, and are good in agreement with experimental values.
\end{abstract}

\section{Keywords: Mist Nozzle, Evaporative Cooling, Spinning Disc Atomization}

\section{INTRODUCTION}

The air conditioning system is a foremost energy consuming commodity in the domestic and industrial applications to maintain the air temperature and humidity in the space. The building sector is the major contributor to the energy consumption; it consumes about $50 \%$ of the world energy consumption. In domestic and commercial premises, air conditioning systems consume about $30 \%$ of electricity. Lot of research work is carried out in evaporative cooling techniques such as direct evaporative cooling, indirect evaporative cooling, combined direct and indirect evaporative cooling, different types of cooling media and materials etc in order to improve the energy efficiency and cooling capacity.

Igor et al. [1] have developed a numerical model for direct evaporative cooler having a compact metallic air/water interface to predict the outlet air temperature. The predicted and experimental results are compared and observed with $1.33 \%$ maximum error. J.M. Wu et al. [2] have theoretically investigated the exchange of energy and concentration among the air stream and water mist particles and proposed the simplified correlation to find the cooling efficiency. Chenguang Sheng et al. [3] have analyzed the effect of performance parameters as frontal air velocity, inlet air temperature and incoming water temperature on the cooling effect produced by the system. An empirical correlation is also developed between the frontal air velocity and the cooling effect produced by the system. G Khater [4] had optimized the factors which are affecting the performance of the cooling process by developing a mathematical model and obtained the results as the saturation efficiency with respect to WBT is 0.9 to 1.0. Riangvilaikul et al. [5] have did an experimental study on the dew point evaporative cooling system and reported the conclusions regarding ambient conditions affecting the system effectiveness ranging from 92 to $114 \%$ and 58 to $84 \%$ to the wet bulb and dew point effectiveness respectively. Kang Zhou [6] had performed the calculation to find evaporation rate of swamp coolers mostly used in arid regions and the mist spray evaporative cooler and remarked as the mist spray evaporative cooling is more efficient as far as water and energy consumption are concerned. Chakrabarti et al.[7] have provided a onedimensional model for mass and energy balance to predict the effect of various parameters as feeding water temperature, air flow rate and air humidity ratio on air temperature inside the air washer heat exchanger. Craig Farnham et al. [8] have experimentally investigated the cooling effect produced by the oscillating mist fan in a large indoor space and recorded the drop in temperature by 0.2 to $2.5 \mathrm{~K}$ with $5 \%$ rise in local humidity. The average cooling effect due to mist and fan is increased by $14 \%$, compared to the cooling effect produced without misting system or fan alone. Akintunji et al. [11] have studied the theoretical model of feasibility index to 
evaluate the potential of the evaporative cooler month wise in Niamey, Niger Republic. The feasibility index depends on the difference between the WBT and the wet bulb depression and it helps to decide the effectiveness of evaporative cooler achieving the comfort conditions.

Literature review shows that the mist generation by using mist nozzle and spinning disc combination is not observed. The objective of the current research is to develop a mist spray direct evaporative cooler (MSDEC) by using the low-pressure mist nozzle and spinning disc, experimental analysis of a MSDEC with a perception of energy saving and maintain the hygiene conditions and develop an empirical correlation to predict the temperature of outlet air temperature (T2).

\section{METHODOLOGY}

MSDEC is developed by using mist nozzle and the spinning disc. These two elements are used to enhance the contact surface area between the air and water particles, which augment the rate of evaporation of water and the cooling capacity.

\section{Development of Mist Nozzle}

Mist nozzle, a device which generates a fine mist of water. The major parts of the mist nozzle are nozzle body, microturbine, and an orifice which are designed, developed and tested. The microturbine is fitted inside nozzle body in order to provide the swirling effect to the water. Orifice leads to accelerating the flow of water through the nozzle. This nozzle reduces the pressure of water which is sufficient to produce a fine spray of water. Figure 1 shows the photograph of the developed nozzle. It is made up of brass material as it has good machining and corrosion resistant properties.

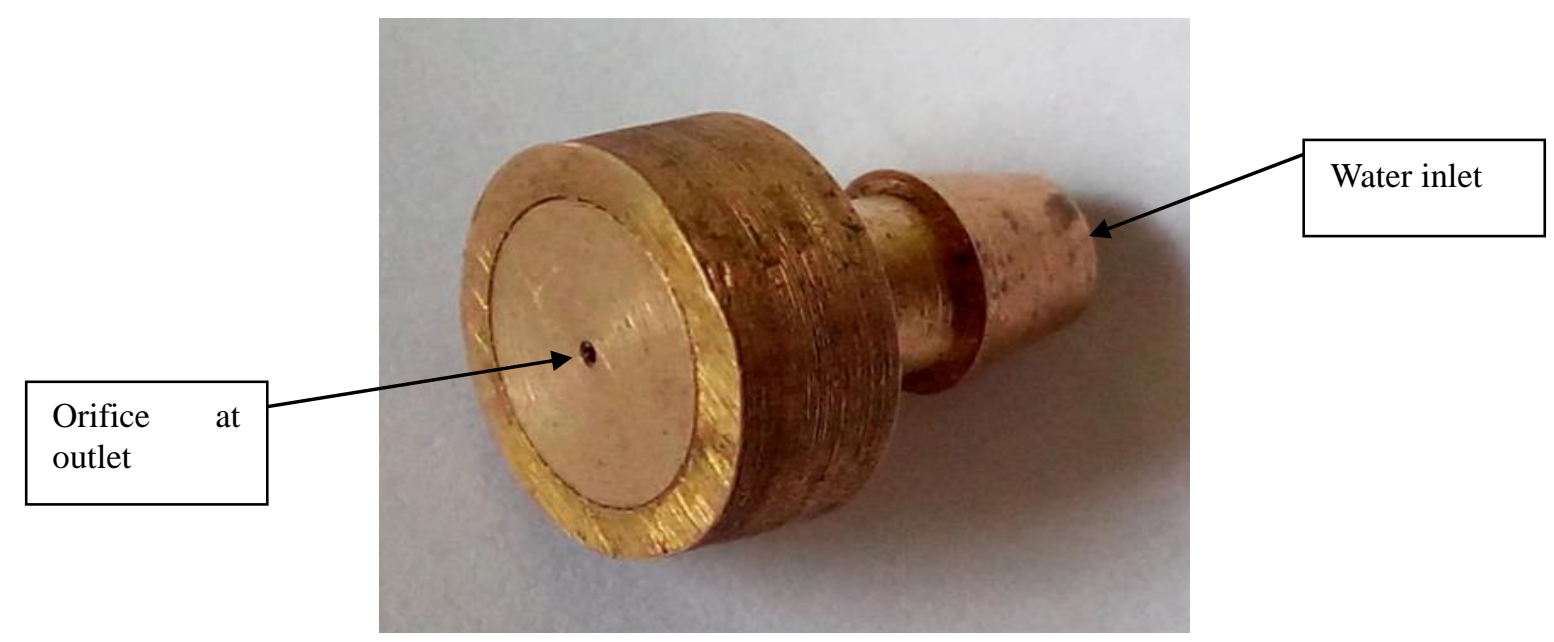

Figure 1. Mist nozzle

\section{Development of Spinning Disc}

The spinning disc as shown in Figure 2 further helps to create a fine mist made available from the nozzle. Specially designed spinning disc is the major component used in this MSDEC which is mounted to the eye of the fan blade. Spinning disc has projected fins along its circumference which advances shearing of water into fine particles and increase the contact surface area of water for evaporation. Spinning disc does not require an additional power source as it is mounted on the eye of the fan blade.

\section{EXPERIMENTAL SETUP}

The block diagram of the experimental setup is as shown in Figure 3. The inlet and outlet air properties dry bulb temperature (DBT), wet bulb temperature (WBT), relative humidity (RH) and mass flow rate of air are measured by using sensor strip (5) and (6) respectively. Sensor strips are connected to the data acquisitions system to record the observations. 


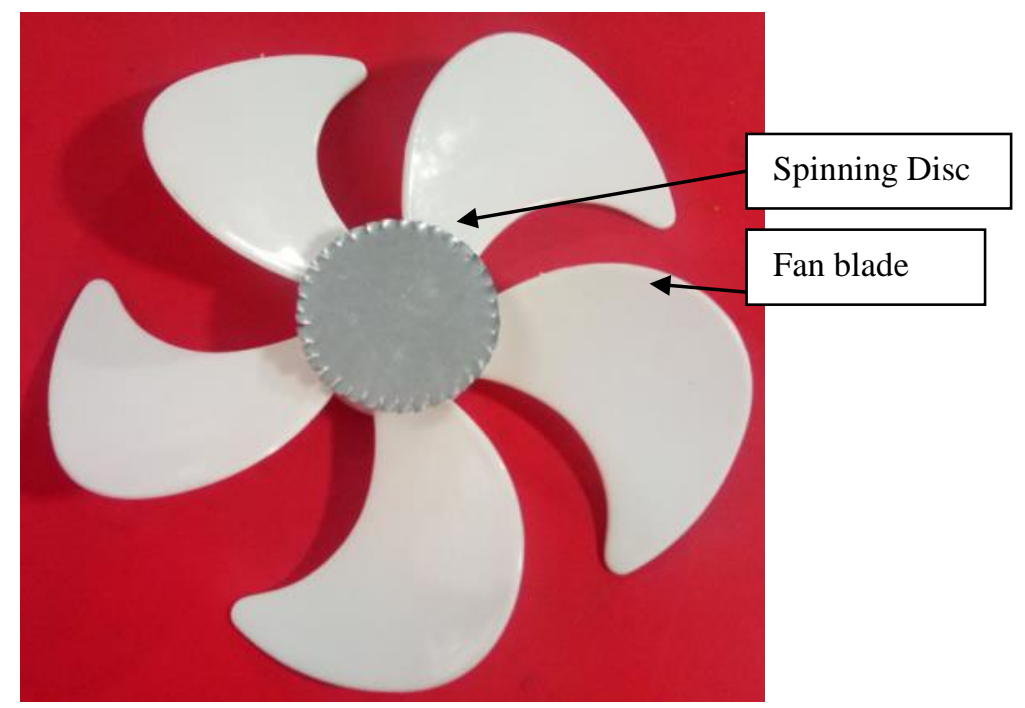

Figure 2. Spinning disc

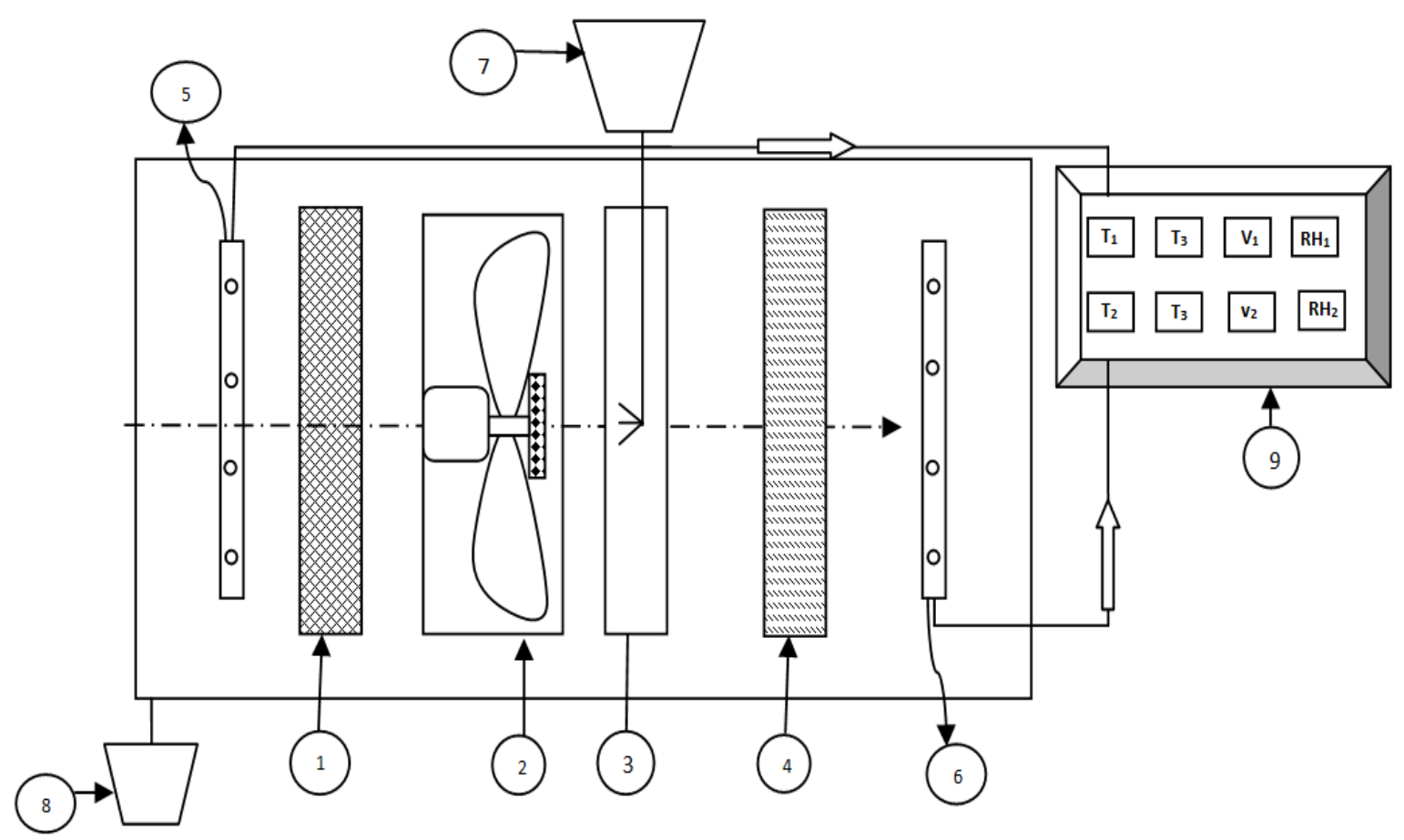

Figure 3. Block diagram of the test setup

$\begin{array}{ll}1 & \text { Air filter } \\ 2 & \text { Fan and spinning disc assembly } \\ 3 & \text { Mist nozzle } \\ 4 & \text { Air damper } \\ 5 & \text { Inlet air properties measuring sensors }\end{array}$

6 Outlet air properties measuring sensors

$7 \quad$ Water tank

8 Drain water tank

9 Data acquisition system

The performance of the MSDEC is a function of the rate of evaporation of water. The rate of water evaporation in cooler depends upon the parameters like DBT, RH, mass flow rate of air and the free contact surface area of the incoming air and water particles. Here, the device is designed to promote dropwise evaporation against film wise evaporation and is the only option for improving the performance of MSDEC which is focused in the present work. In the developed MSDEC, enhancement in air-water contact surface area is achieved by using specially developed innovative nozzle assembly with microturbine and spinning disc together. 


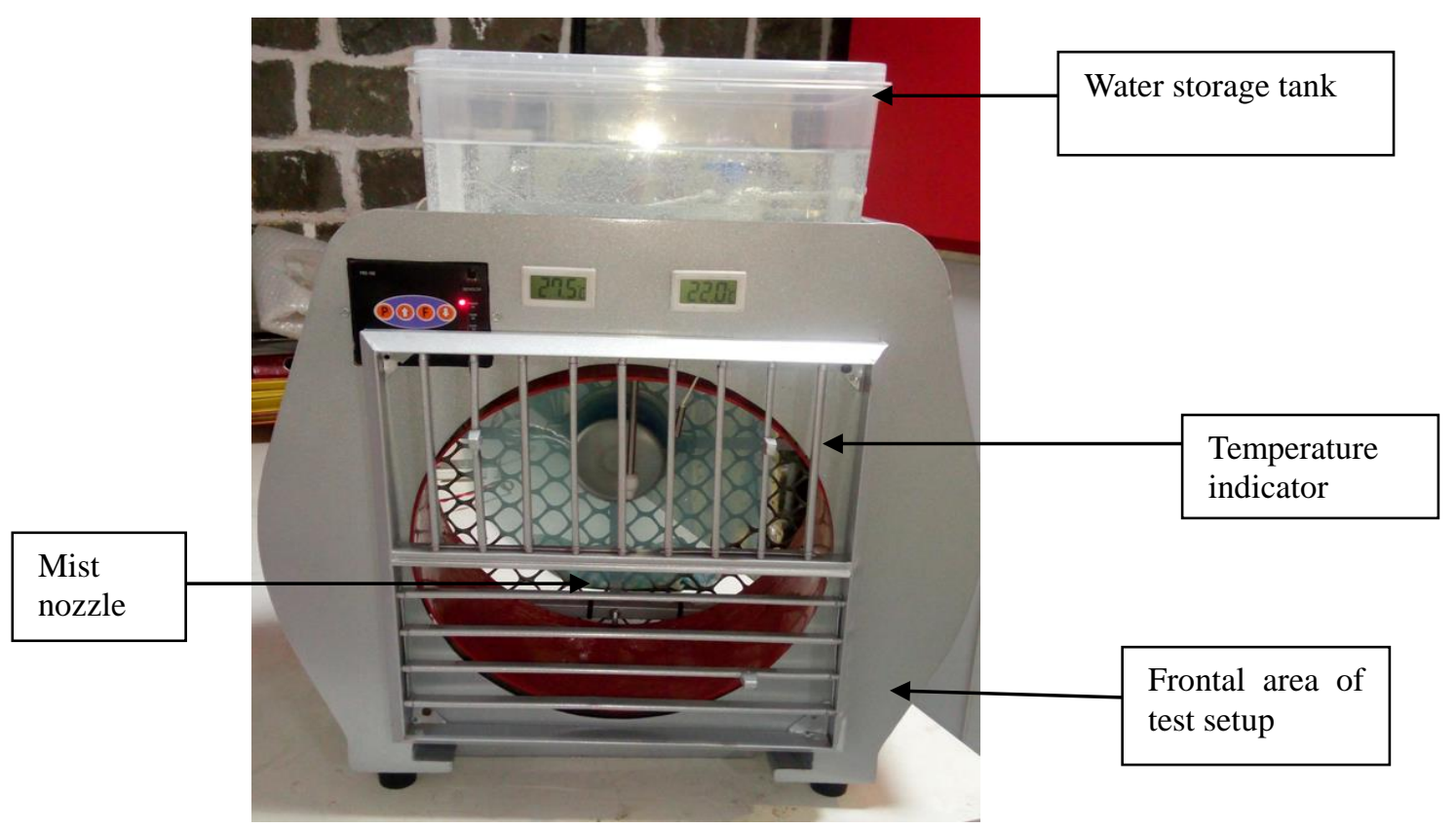

Figure 4. Test setup

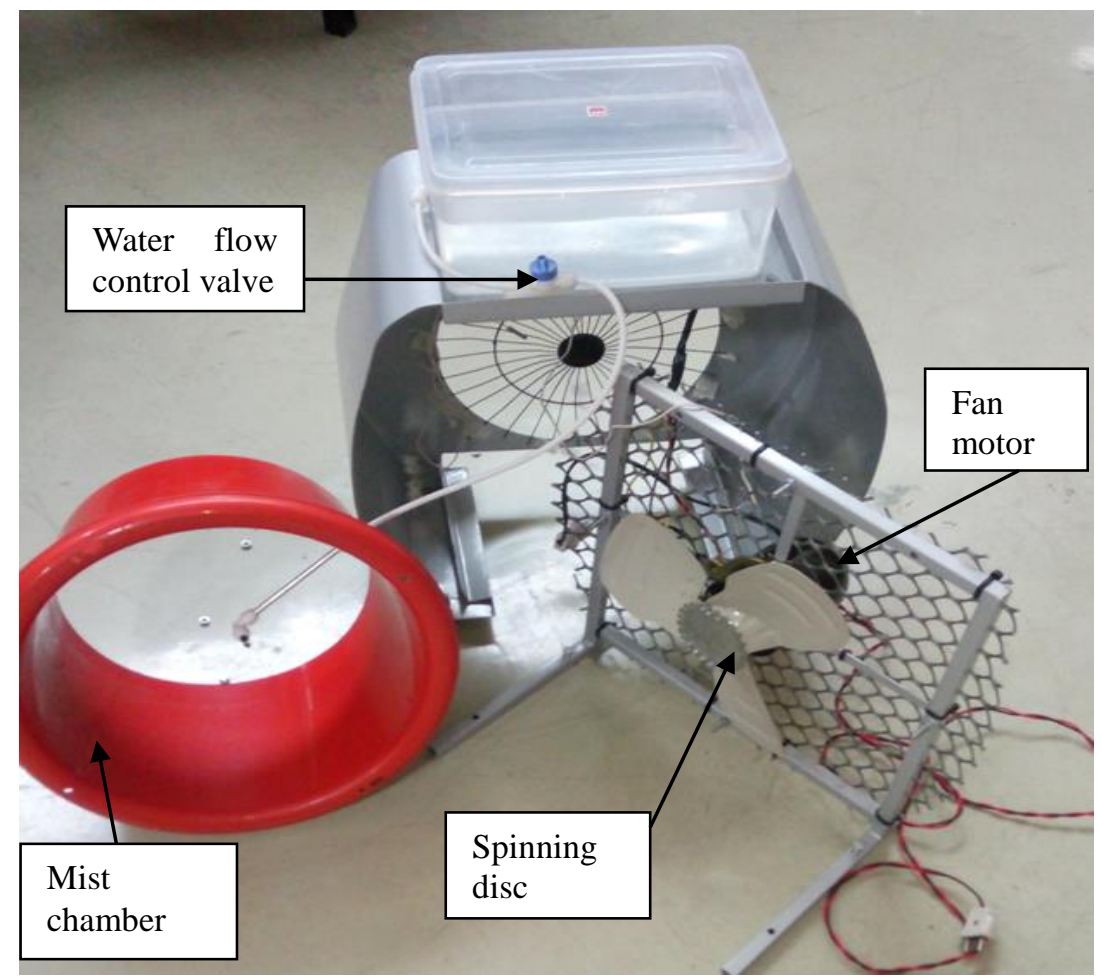

Figure 5. Parts of the test setup

A water storage tank is fitted above the system and the nozzle is connected to the storage tank through a rigid pipe as shown in Figure 4. A water flow control valve is also provided between the storage tank and the nozzle pipe.

Developed MSDEC consists of an axial fan having sweep diameter of $250 \mathrm{~mm}$ and a maximum speed of $2000 \mathrm{rpm}$. The maximum volume flow rate of air of MSDEC is $900 \mathrm{cfm}$ with the maximum input power of 75W. The overall dimensions ( $\mathrm{L}$ x W x H) of the MSDEC are $390 \mathrm{~mm}$ x $390 \mathrm{~mm}$ x $590 \mathrm{~mm}$ respectively. Water storage capacity for the system is 5 liters. 


\section{EXPERIMENTAL PROCEDURE}

Before starting the experiment, measure the DBT and RH of the space to be cooled. Switch on the fan and water flow control valve, measure the velocity at the inlet and outlet section of the evaporative cooler at various fan speeds by using the vane type anemometer. Measure the temperature by using digital temperature indicator having accuracy $\pm 0.5 \mathrm{oC}$ at three different places of outlet section and the outlet temperature (T2) of air is the arithmetic mean of these three readings. WBT (T3) can be obtained by plotting the values of inlet air temperature (T1) and \% RH on the psychrometric chart. By putting the values of T1, T2, T3 and \% RH in the equation 1 and 2 one can calculate the cooling capacity and the saturation efficiency respectively.

$$
\begin{gathered}
\text { Cooling capacity } Q=\dot{m} C p_{\text {air }}\left(T_{1}-T_{2}\right) \\
\text { Saturation efficiency } \eta=\frac{T_{1}-T_{2}}{T_{1}-T_{3}}
\end{gathered}
$$

During experimentation mainly DBT and \% RH of the inlet air are measured. By varying the mass flow rate of air and keeping water flow rate constant, the cooling capacity and the saturation efficiency are obtained. The mass flow rate of the air is varied by varying fan speed.

\section{Uncertainty Analysis}

Saturation efficiency is one of the performance parameters of the MSDEC. It is the function of air temperature, velocity and the relative humidity. Details of the TESTO 410-2, air velocity, temperature and relative humidity measuring instrument are given in Table 1.

Table 1. Instrument specifications

\begin{tabular}{|c|c|c|}
\hline \multicolumn{2}{|c|}{ Instrument make: TESTO } & Model: 410-2 \\
\hline Parameter & Range & Accuracy \\
\hline Temperature & -10 to $50 \mathrm{oC}$ & $\pm 0.5 \mathrm{oC}$ \\
\hline Relative humidity & 0 to $100 \%$ & $\pm 2.5 \%$ \\
\hline Velocity & 0.4 to $20 \mathrm{~m} / \mathrm{s}$ & $\pm 0.4 \mathrm{~m} / \mathrm{s}$ \\
\hline
\end{tabular}

By using the Weakest Link Rule to determine the absolute uncertainty of the system, the largest relative uncertainty from all measured relative uncertainties is considered. As shown in Table 2, the largest relative uncertainty is $5.71 \%$ for a set of sample observation. For this sample calculation, the saturation efficiency is $75 \%$ with the uncertainty of 5.71

Table 2. Sample observation to measure the uncertainty

\begin{tabular}{|c|c|c|}
\hline Property of air & $\begin{array}{c}\text { Value with absolute } \\
\text { uncertainty }\end{array}$ & Relative uncertainty \% \\
\hline Temperature & $(30 \pm 0.5) \mathrm{oC}$ & $0.5 / 30=0.0166=1.16$ \\
\hline Relative humidity & $(45 \pm 2.5) \%$ & $2.5 / 45=0.0555=5.55$ \\
\hline Velocity & $(7 \pm 0.4) \mathrm{m} / \mathrm{s}$ & $0.4 / 7=0.0571=5.71$ \\
\hline
\end{tabular}

\section{RESULTS AND DISCUSSIONS}

The performance evaluation of a MSDEC is carried out experimentally. Tests are conducted for different mass flow rates of air. The drop in temperature of air with respect to variation in mass flow rate of air is measured. The saturation efficiency of the MSDEC increases with respect to the rise in the mass flow rate of air up to the certain limit and again it starts to decline. The mist nozzle produces fine water particles which are sprayed on the rotating spinning disc. These water particles are propelled outward due to centrifugal action along the outward surface of the disc and strikes to the projected fins provided on the periphery of the spinning disc. 
The projected fins on the disc again shear the water particles into tiny particles, which enhance the contact surface area between water particles and a warm stream of inlet air.

During experimentation, mass flow rate of air is varied from 0.2 to $0.7 \mathrm{~kg} / \mathrm{s}$. It is observed that the saturation efficiency first increases with respect to rise in the mass flow rate of air and reaches to the maximum value of $87 \%$ at $0.5 \mathrm{~kg} / \mathrm{s}$ and after that, it starts decreasing as shown in Figure 6.

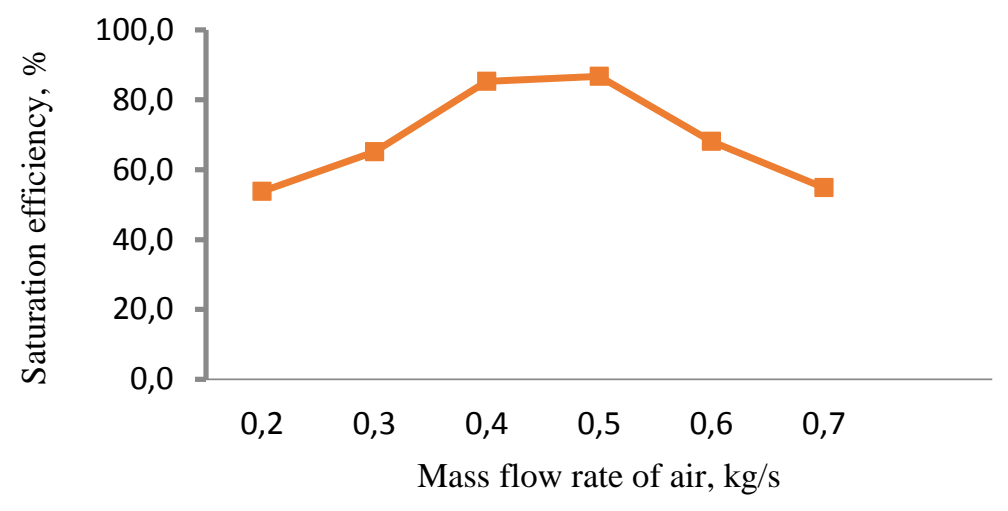

Figure 6. Variation of saturation efficiency with the variation of mass flow rate of air

The coefficient of performance of a cooling system is the ratio of cooling effect to the energy input. COP of MSDEC varying with respect to change in mass flow rates of air from 0.2 to $0.7 \mathrm{~kg} / \mathrm{s}$ is presented in Figure 7. The experimental results show the COP of a MSDEC is in the range of 20 to 45. The reason for higher cooling capacity is an increase in contact area between the air and water particles on account of a mist nozzle and spinning disc arrangement which leads to increase in cooling effect for the constant energy input. It is observed that the maximum COP is obtained at a mass flow rate of air at $0.5 \mathrm{~kg} / \mathrm{s}$ and after which COP of the system starts decreasing. The COP of the system is reducing at higher mass flow rate of air, due to the comparatively large mass of air stream and the less quantity of water particles. From Figure 6 and 7, one could conclude that the optimum operating mass flow rate of air is $0.5 \mathrm{~kg} / \mathrm{s}$ for the employed cooling system.

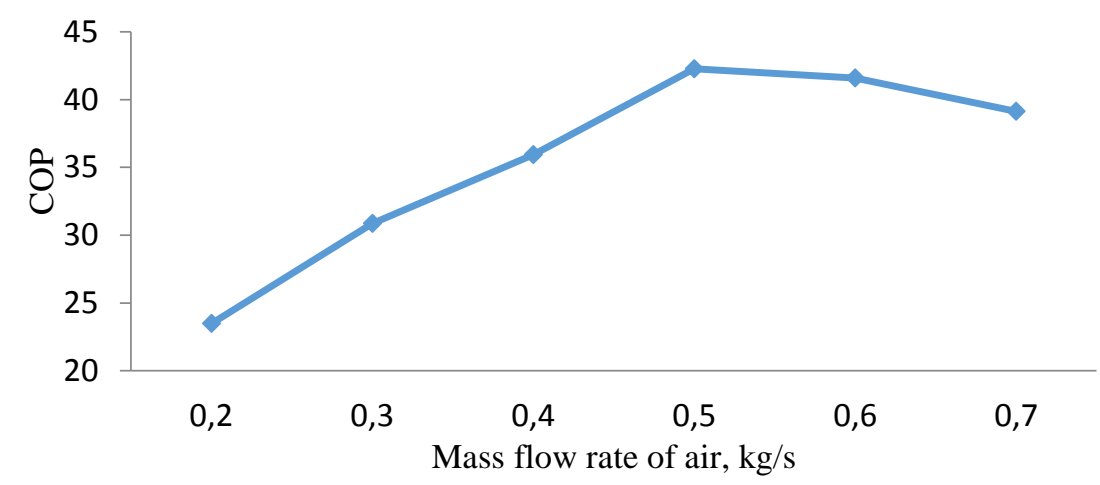

Figure 7. Variation of coefficient of performance with the variation of mass flow rate of air

Figure 8 shows the effect of ambient air temperature and inlet air velocity on the outlet air temperature. Here the outlet temperature is expressed in the dimensionless form as (drop in temperature per unit inlet temperature). The ambient temperatures are 30, 35, 40 and $43^{\circ} \mathrm{C}$ and inlet air velocities $2.8,3.8,4.2$ and $5.2 \mathrm{~m} / \mathrm{s}$ are considered. It indicates that the ratio of the drop in temperature per unit inlet air temperature increases with respect to rising in air velocity. As the ambient temperature increases from $30^{\circ} \mathrm{C}$ to $43^{\circ} \mathrm{C}$, the drop in temperature i.e. the difference between the inlet and outlet air temperature increases which helps to increase the cooling capacity of the system. From the graph shown in Figure 8, one concludes that the system performs efficiently in the hot and dry climate than the cold and humid climate. 


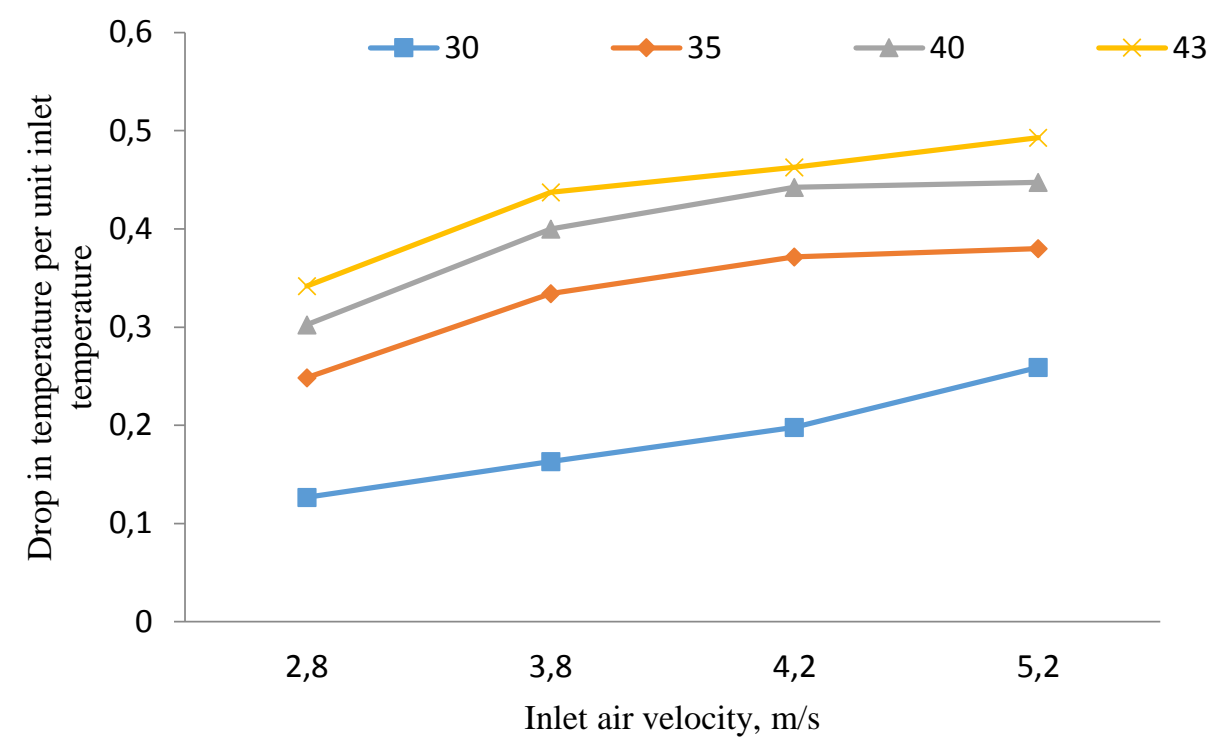

Figure 8. Outlet air temperature per unit inlet temperature at various inlet air velocities

\section{DEVELOPMENT OF EMPIRICAL CORRELATION}

Through experimentation, one can predict the dependent variable which depends on one or more independent variable by using the regression analysis. The regression analysis is done using the software Minitab 17. In this paper, the regression analysis is done on 25 sets of experimental readings for different ambient conditions using such data after regression analysis one can predict the outlet air temperature $\mathrm{T}_{2}$ of the MSDEC by using the empirical correlation

$$
T_{2} \text { predicted }=5.52+\left(0.394 T_{1}\right)+(0.0042 R H)+(439 \omega)
$$

This empirical correlation is best fitted for the temperature range of $25^{\circ} \mathrm{C}$ to $40^{\circ} \mathrm{C}$ and relative humidity in the range of 10 to $80 \%$. The predicted temperature calculated the empirical correlation and the measured outlet temperature in experiment are close to each other within $8 \%$. The Figure 9 shows the predicted cooled cooled air temperature calculated with the help of developed empirical correlation and the values cooled air temperatures measured experimentally, which are in good agreement.

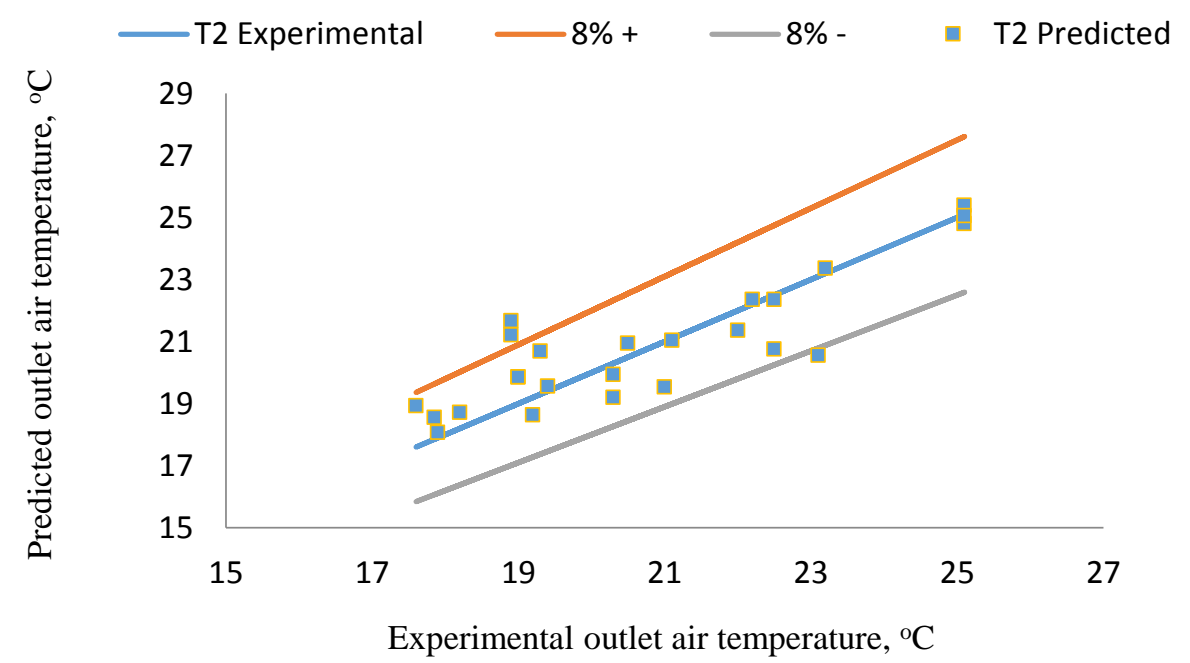

Figure 9. Comparison of outlet air temperature 


\section{CONCLUSION}

An innovative MSDEC contains newly developed low-pressure nozzle, spinning disc and axial fan. The mist is generated with the help of mist nozzle and the spinning disc. The performance parameters say saturation efficiency and cooling capacity of MSDEC are obtained through experimentation. So saturation efficiency of the air is recorded up to $87 \%$ and the cooling capacity up to $3.5 \mathrm{~kW}$. The COP of the system ranges from 20 to 45 . It is also observed that the performance parameters are almost linearly varying with the mass flow rate of the air up to $0.5 \mathrm{~kg} / \mathrm{s}$, after this value it starts to decrease.

Based on the experimental data an empirical correlation is developed by using fit regression model. The predicted cooled air temperature by using the developed empirical equation and the experimental values of the cooled air temperature are in good agreement or more precisely they are in the order of $\pm 8 \%$. This developed MSDEC could be modified for different industrial applications, especially where the higher humidity of air is required to be maintained such as textile industry, fruit and vegetable storages. Air pre-cooler in Air conditioning systems can also be used in polyhouse to maintain temperature and humidity.

\section{NOMENCLATURE}

$\begin{array}{ll}\text { MSDEC } & \text { mist spray direct evaporative cooler } \\ \text { DECHPA } & \text { direct evaporative cooler with honeycomb pad arrangement } \\ \text { DBT } & \text { dry bulb temperature }\left[{ }^{\circ} \mathrm{C}\right] \\ \text { WBT } & \text { wet bulb temperature }\left[{ }^{\circ} \mathrm{C}\right] \\ \text { COP } & \text { coefficient of performance } \\ \text { HVAC } & \text { heating ventilation and air conditioning } \\ \dot{m} & \text { mass flow rate }[\mathrm{kg} / \mathrm{s}] \\ \text { Cpair } & \text { specific heat of moist air }[\mathrm{kJ} / \mathrm{kg} \mathrm{K}] \\ \text { T1 } & \text { inlet air DBT }\left[{ }^{\circ} \mathrm{C}\right] \\ \text { T2 } & \text { outlet air DBT }\left[{ }^{\circ} \mathrm{C}\right] \\ \text { T3 } & \text { inlet air WBT }\left[{ }^{\circ} \mathrm{C}\right] \\ \text { RH } & \text { relative humidity }[\%] \\ \text { Q } & \text { cooling capacity }[\mathrm{kW}] \\ \eta & \text { saturation efficiency }[\%] \\ \omega & \text { specific humidity of inlet air }[\mathrm{kg} / \mathrm{kg} \text { of dry air] } \\ \mathrm{p}_{\mathrm{v}} & \text { partial pressure of water vapor }[\mathrm{kPa}] \\ \mathrm{p}_{\mathrm{s}} & \text { partial pressure at saturated temperature }[\mathrm{kPa}]\end{array}$

\section{REFERENCES}

[1] Kovačević, I., Sourbron, M. (2017). The numerical model for direct evaporative cooler. Applied Thermal Engineering, 113, 8-19.

[2] Wu, J. M., Huang, X., Zhang, H. (2009). Theoretical analysis on heat and mass transfer in a direct evaporative cooler. Applied Thermal Engineering, 29(5-6), 980-984.

[3]Sheng, C., \& Nnanna, A. A. (2011, January). Empirical correlation of cooling efficiency and transport phenomena of direct evaporative cooler. In ASME 2011 International Mechanical Engineering Congress and Exposition (pp. 953-967). American Society of Mechanical Engineers.

[4] Khater, E. S. G. (2014). Performance of Direct Evaporative Cooling System under Egyptian Conditions. Journal of Climatology \& Weather Forecasting, 2.

[5] Riangvilaikul, B., Kumar, S. (2010). An experimental study of a novel dew point evaporative cooling system. Energy and Buildings, 42(5), 637-644.

[6] Zhou, K. (2014). Calculation of Evaporation Rate of a Droplets Cluster and Conceptual Design of a Structure Utilizing Water Droplets for Evaporation. Hydrology: Current Research, 5(3), 1.

[7] Chakrabarti, S. S., Bhandarkar, L. R., Vijawargiya, A., Nageshwar Rao, P. S. R. K. (2015). A mathematical approach in the formulation of a direct evaporative cooling device, International Journal of Engineering Research \& Technology (IJERT), 4, 02.

[8] Farnham, C., Zhang, L., Yuan, J., Emura, K., Alam, A. M., Mizuno, T. (2017). Measurement of the evaporative cooling effect: oscillating misting fan. Building Research \& Information, 45(7), 783-799. 
[9] Santos, J. C., Barros, G. D. T., Gurgel, J. M., Marcondes, F. (2013). Energy and exergy analysis applied to the evaporative cooling process in air washers. International Journal of Refrigeration, 36(3), 1154-1161.

[10] Farnham, C., Nakao, M., Nishioka, M., Nabeshima, M., Mizuno, T. (2011). Study of mist-cooling for semienclosed spaces in Osaka, Japan. Procedia Environmental Sciences, 4, 228-238.

[11] Akintunji, L. L., Ibrahim U. Haruna, Bello S. Momoh. (2014). Theoretical evaluation of the potential of evaporative cooling for human comfort using feasibility index (Fi) model, International Journal of Scientific Technology Research, 3, 3.

[12] Huang, X., Chen, L., Kang, Y., Lei, M., Chu, J. (2017). The applicability and application of evaporative cooling in countries around 'The belt and road initiative'. Procedia Engineering, 205, 233-240.

[13] Kachhwaha, S. S., Dhar, P. L., Kale, S. R. (1998). Experimental studies and numerical simulation of evaporative cooling of air with a water spray-I. horizontal parallel flow. International Journal of Heat and Mass Transfer, 41(2), 447-464.

[14] Turkyilmazoglu, M., Cole, J. W., Gajjar, J. S. B. (2000). Absolute and convective instabilities in the compressible boundary layer on a rotating disk. Theoretical and Computational Fluid Dynamics, 14(1), 21-37. 